INTERFACE

royalsocietypublishing.org/journal/rsif

Research

Check for updates

Cite this article: Macchi R, Daver G, Brenet $M$, Prat $S$, Hugheville L, Harmand S, Lewis J, Domalain M. 2021 Biomechanical demands of percussive techniques in the context of early stone toolmaking. J. R. Soc. Interface 18: 20201044.

https://doi.org/10.1098/rsif.2020.1044

Received: 24 December 2020

Accepted: 29 April 2021

\section{Subject Category:}

Life Sciences-Earth Science interface

\section{Subject Areas:}

biomechanics, evolution

\section{Keywords:}

stone toolmaking, Lomekwian, hominins, motor control, kinematics, electromyography

\section{Author for correspondence:}

M. Domalain

e-mail: mathieu.domalain@univ-poitiers.fr

Electronic supplementary material is available online at https://doi.org/10.6084/m9.figshare. c.5427702.

\title{
Biomechanical demands of percussive techniques in the context of early stone toolmaking
}

R. Macchi ${ }^{1,2}$, G. Daver ${ }^{2}$, M. Brenet ${ }^{3}$, S. Prat ${ }^{4}$, L. Hugheville ${ }^{5}$, S. Harmand ${ }^{6}$, J. Lewis ${ }^{6}$ and M. Domalain ${ }^{1}$

${ }^{1}$ Institut PPrime, CNRS - Université de Poitiers - ENSMA, UPR 3346, Poitiers, France

${ }^{2}$ PALEVOPRIM, CNRS - Université de Poitiers, UMR 7262, Poitiers, France

${ }^{3}$ CNRS, UMR5199 PACEA et INRAP GSO, Université de Bordeaux, 33615 Pessac, France

${ }^{4}$ UMR 7194 (HNHP), MNHN/CNRS/UPVD, Alliance Sorbonne Université, Musée de l'Homme, Paris, France

${ }^{5}$ Institut du Cerveau et de la Moëlle épinière, Paris, France

${ }^{6}$ Turkana Basin Institute, Department of Anthropology, Stony Brook University, Stony Brook, NY 11794-4364, USA

(iD) MD, 0000-0002-4518-8479

Recent discoveries in archaeology and palaeoanthropology highlight that stone tool knapping could have emerged first within the genera Australopithecus or Kenyanthropus rather than Homo. To explore the implications of this hypothesis determining the physical demands and motor control needed for performing the percussive movements during the oldest stone toolmaking technology (i.e. Lomekwian) would help. We analysed the joint angle patterns and muscle activity of a knapping expert using three stone tool replication techniques: unipolar flaking on the passive hammer (PH), bipolar (BP) flaking on the anvil, and multidirectional and multifacial flaking with free hand (FH). PH presents high levels of activity for Biceps brachii and wrist extensors and flexors. By contrast, BP and FH are characterized by high solicitation of forearm pronation. The synergy analyses depict a high muscular and kinematic coordination. Whereas the muscle pattern is very close between the techniques, the kinematic pattern is more variable, especially for PH. FH displays better muscle coordination and conversely lesser joint angle coordination. These observations suggest that the transition from anvil and hammer to freehand knapping techniques in early hominins would have been made possible by the acquisition of a behavioural repertoire producing an evolutionary advantage that gradually would have been beneficial for stone tool production.

\section{Introduction}

Stone toolmaking is considered a hallmark of humankind and its acquisition represents a major evolutionary advance in hominin evolution. Recent contributions in archaeology, palaeoanthropology and evolutionary biomechanics proposed that the earliest known representatives of the genus Homo (2.8 million years ago (Ma), Ledi Geraru, Ethiopia [1]) may not have been the first hominin stone toolmaker as originally proposed by Leakey et al. [2]. Indeed, early nonHomo hominins between 3 and 4 Ma [3-5] were presumably able to fulfil some of the functional requirements needed for stone toolmaking. Especially, it has been inferred from paleoanthropological analyses that Australopithecus afarensis would have been capable of many human-like manipulative capabilities, especially if hammering [3,4,6-9], while biomechanical simulations of hand functions further confirmed that this hominin was capable of human-like grips [10,11], despite local functional limitations [12], validating Marzke's (1983) inferences [7]. Concurrently, the possibility that stone tool knapping could have emerged with the genus Australopithecus was suggested from the Oldowan assemblage from Gona, Ethiopia [13], and the possible hammerstone percussion evidence found at Dikika (3.39 Ma, Ethiopia) [14] (but see [15]) both 

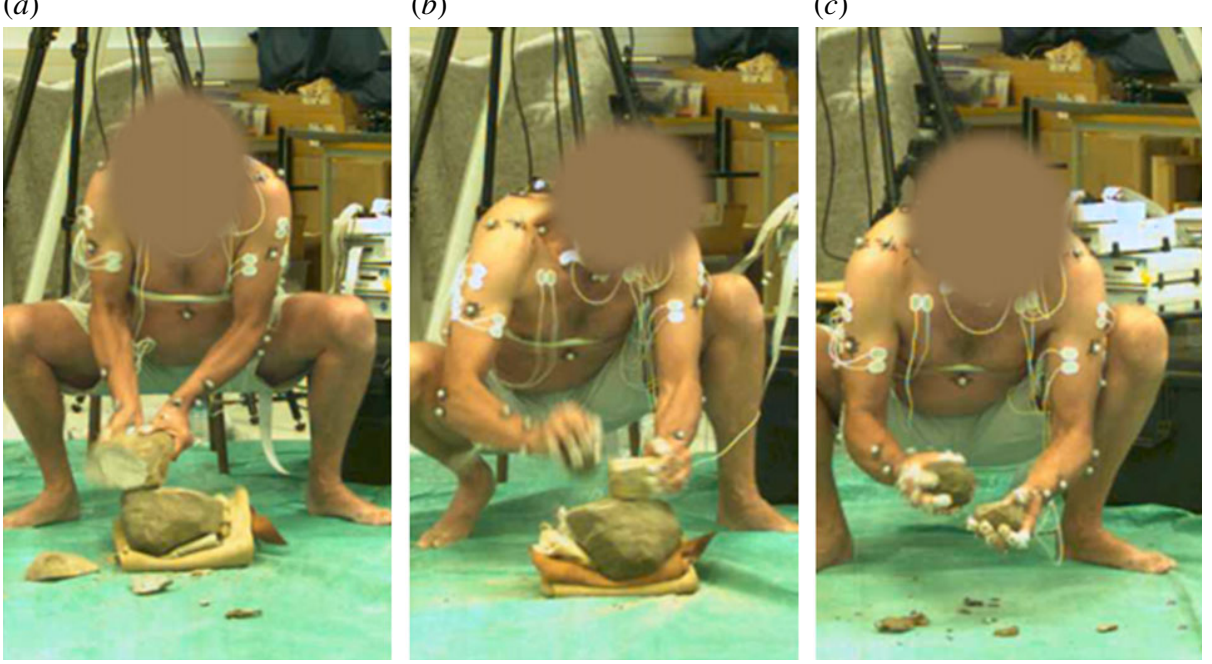

Figure 1. Percussive techniques used for this study: (a) unipolar flaking on the passive hammer (PH), (b) bipolar flaking on the anvil (BP) and (c) multidirectional and multifacial flaking with free hand $(\mathrm{FH})$.

sharing the same geochronological context as, respectively, $A u$. garhi and Au. afarensis. The discovery of the stone tools from Lomekwi 3 (3.3 Ma, West Turkana, Kenya) provides evidence of an early emergence of stone tool knapping activities, 500000 years ago (ka) before the first fossil occurrence of early Homo [16] (but see [17]).

As opposed to the Oldowan technocomplex, the Lomekwian stone tools assemblage exhibits exceptionally larger and heavier flakes (around $0.8 \mathrm{~kg}$ ) and cores (around $3 \mathrm{~kg}$ ) in addition to recognizable knapping activity marks [16]. From analysis of these technological and morphological features, and stone tool replication experiments, two percussive techniques - the bipolar (BP) flaking on the anvil, and the unipolar flaking on passive hammer $(\mathrm{PH})$ techniques-have been inferred to have been the most frequently used during knapping at the site (figure 1) $[16,18]$. In the BP technique, the core is rested on an anvil (which itself is likely laying on the ground) and held in place with the non-dominant hand, and struck along its edges with a hammerstone held by the dominant hand $[19,20]$. In the $\mathrm{PH}$ technique, the core is held with both hands and swung down and struck against an anvil (thus, the immobile anvil is acting passively as the hammerstone) $[16,19]$. These two percussive techniques differ from the free hand $(\mathrm{FH})$ percussive technique dominant in Oldowan technology and correspond with multidirectional flaking. In the latter, the hammerstone is held by the dominant hand and the core maintained by the non-dominant hand without the help of an anvil $[19,20]$. Inversely, those techniques identified at Lomekwi recall the hammer-on-anvil technique used by common chimpanzees, capuchins and macaques when engaged in nut-cracking and shell crushing. Indeed, it can be performed in a unimanual (like in BP) or bimanual fashion (like in PH) [21-23]. As a result, the three archaeological techniques underline two contrasting conditions, namely 'with anvil' versus 'without anvil' and 'unimanual' versus 'bimanual'. As such, they are expected to involve specific biomechanical demands including muscle and joint solicitation. The biomechanical demands of some of these knapping activities have been analysed using kinematic and electromyographic approaches. For instance, previous studies of FH percussive techniques emphasized high solicitation of wrist extension during the down-swing [24], suggesting that the flexor-extensor apparatus helps either in stabilizing the elbow joint during the strike [25] or in accelerating the hammerstone towards the target [26,27]. Thus, the analysis of upper limb movement during stone toolmaking replications provides a means of investigating the functional demands required for making the oldest stone tools and exploring the hypothesis of Australopithecus or Kenyanthropus being a possible stone tool maker.

Human motor behaviour is highly goal-directed. This requires the central nervous system (CNS) to coordinate different aspects of motion generation to achieve the motion goals. Using the terminology introduced by Latash et al. [28], the CNS organizes the control of elemental variables to stabilize performance variables. Joint degrees of kinematic freedom, activation of muscles and joint torques can all be considered as elemental variables. Performance variables are directly related to the task goal: in the frame of stone tool knapping, point of percussion and angle of blow can be performance variables [29]. The concept of motor synergies (i.e. muscle or kinematic synergies) provides an approach to quantify the covariation of the elemental variables during a task. A motor synergy can be defined as a set of stable spatio-temporal patterns of activity shared across elemental variables that leads to a desirable performance variable. It has been suggested that the CNS may generate motor commands through a linear combination of motor synergies, each controlling a group of elemental variables (see [30] for a review). Such coactivation of elemental variables leads to a reduction in the dimensionality of motor control. Numerous studies have demonstrated that a range of functional tasks can be explained by motor synergies, including stone knapping [31]. Muscle synergies have also been able to discriminate between grasps of differently shaped objects in a non-human primate [32] and, more generally, they are known to be task specific and reflect the biomechanical constraints of the task [33]. To quantify motor synergies, dimensionality reduction methods are used to analyse large sets of muscle activity or joint angle changes observed over the course of motor tasks. Principal component analysis (PCA) allows quantifying complexity as how much variance of the movement can be reduced to single dimension component. Interestingly, similar multivariate methods are used to reconstruct muscle synergy groups based on muscle entheses (i.e. muscle and ligament attachment sites on bone [25] which are the only remains of the musculotendinous unit in fossils) [34-36]. In the case of 
the stone knapping task, the variance accounted for by the first principal component (PC1) significantly depends on the conditions of the motor task and can be interpreted as a measure of the complexity of movement control for the CNS [37]. Based on the above-mentioned concepts, stone tool production has been interpreted as being diagnostic of the cognitive and motor skills of extinct hominins [38,39]. Bril et al. [40] argue that the transition from anvil and hammer percussive techniques to freehand knapping techniques in early hominins necessitated improved motor control superior to that of non-human primates. Motor skills might have been the most important, as a cognitive development without the ability for execution will not yield an evolutionary advantage [41-43]. While Bril et al. [38] showed that nut-cracking and stone knapping implied equivalent skills and rates of success, they also demonstrated highly significant differences. Indeed, both conditions 'with anvil' versus 'without anvil' and 'unimanual' versus 'bimanual' influence the manipulative complexity of the task [43] and underline the evolutionary role of the non-dominant (i.e. postural) hand [38].

Consequently, the aim of this study was to compare $\mathrm{PH}$, $\mathrm{BP}$ on anvil and $\mathrm{FH}$ knapping techniques in terms of biomechanical and motor control demands in an evolutionary perspective. We first hypothesized (H1) that technique output would be comparable so that technique may be reduced to its fundamental striking element [44]. Biomechanical demands of the strikes were assessed through the amplitude of muscle activity and joint mobility of the upper limbs. Based on previous studies we expected, for all three techniques, a high muscle activity of Extensor and Flexor carpi ulnaris, Triceps brachii and Pectoralis major muscles $[3,11,25,27]$. Due to the heavier stone involved, we further hypothesized (H2) that $\mathrm{PH}$ technique would elicit greater muscle activity compared to the other techniques.

For all three techniques we expected a high wrist flexionextension [27] but little joint excursion for the shoulder and elbow joints, especially for BP and FH [31]. Due to the heavier stone manipulated, we hypothesized (H3) that the $\mathrm{PH}$ technique involves overall smaller upper limb joint excursions.

As for a motor control point of view, based on interpretations of nut-cracking [38] we expected the $\mathrm{PH}$ technique to be less complex than the other two. To address this issue, we relied on data processing techniques based on PCA to detect 'coordinative structures', or 'synergies' by which the motor system organizes an action [45-47]. We, therefore, used PCA (detailed in the Data analysis and statistics sub-section) as a measure for the complexity of joint and muscle coordination patterns. More precisely, we hypothesized (H4) that the first component will account for a greater percentage of variance for the $\mathrm{PH}$ technique and that loading factors would be higher, both in terms of kinematics and muscle activity. This would indicate lesser motor control demands and potentially a less complex technique.

\section{Material and methods}

\subsection{Participant}

One male subject (age $=58$ years; height $=1.77 \mathrm{~m}$; mass $=80 \mathrm{~kg}$ ) participated in the study after giving his written informed consent. He had no previous history of neuropathies or trauma to the upper extremities. The participant (M.B.) is a recognized expert in stone tool replication [48]. Expertize is defined here as the knowledge of the lithic production schemes and the ability to detach flakes similar to those found in archaeological excavations. This necessitates long-time experience and long-lasting specific training [48-50].

\subsection{Lithic material}

Petrographic variation of raw materials may influence flake production processes, as documented from Pliocene and early Pleistocene sites in the region $[51,52]$. The raw materials for the replications were sourced directly from the conglomerate located a few hundred metres away from the LOM3 site in West Turkana (see source in Harmand et al. [16]) and imported to France. Two anvils (6.7 and $13 \mathrm{~kg}$ ) and two hammerstones ( 0.8 and $1.2 \mathrm{~kg}$ ) were used, consisting of basalt blocks and cobbles. Blocks $(n=9)$ to be reduced were of phonolite and weighted between 0.27 and $5.7 \mathrm{~kg}$.

\subsection{Experimental design}

Three flake production strategies were investigated: unipolar flaking on the $\mathrm{PH}, \mathrm{BP}$ flaking on anvil and multidirectionalmultifacial flaking with $\mathrm{FH}$ percussion (figure 1). Originally, four core reduction sessions (each involving a new core) were performed for each technique but, due to synchronization issues, only four, three and two were retained for $\mathrm{PH}, \mathrm{BP}$ and $\mathrm{FH}$, respectively. The three percussive techniques were randomized to avoid any habituation effect. Thirty-minute rest periods were ensured between each session/trial in order to limit the influence of fatigue. The use of a chair was banned to favour natural postures in accordance with previous observations in humans [53] and chimpanzees $[21,54,55]$. Despite this postural constraint, the expert had to find a unique posture and keep it throughout the replication sessions. The participant consistently adopted a crouched posture (figure 1) during all sessions, and was free to adapt his pace, reposition the anvil and handle the blocks and/or the hammerstones throughout the sessions. The instruction was to complete a series of strikes until it was no longer possible to detach flakes exceeding $1.5 \mathrm{~cm}$ long. Prior to the replication sessions, maximal voluntary isometric contractions (MVCs) were performed.

\subsection{Kinematics}

Joint angle analysis resulted from the following procedure: 55 reflective markers were placed on anatomical landmarks of the trunk and upper limbs. The marker set (adapted from Blache et al. [56-58]) is detailed in electronic supplementary material, table S1. The three-dimensional location of the markers was recorded using a 16-camera optoelectronic system (16 MPixels Oqus camera, Qualisys Inc., Sweden). The sample frequency was set to $300 \mathrm{~Hz}$. A least-square optimization-based inverse kinematic algorithm that minimized the distance between theoretical and experimental marker locations was used to compute joint angles with the OpenSim software [59]. The kinematic model originated from Rajagopal [60] and was scaled to the expert's anthropometry before the calculation of the following joint angles: shoulder, elbow-forearm and wrist flexion/extension (labelled shoulder_flex, wrist_flex and elbow_flex, respectively); shoulder and wrist adduction/abduction angle (labelled shoulder_add, wrist_add, respectively); shoulder medial/lateral rotation (labelled shoulder_rot); and forearm pronation/supination (labelled forearm_pron). Suffix '_d' or '_nd' is added to each abbreviation to discriminate between the dominant versus non-dominant limb, respectively (e.g. shoulder_flex_nd). Negative angles denote extension, abduction, external rotation and supination. 


\subsection{Electromyography}

To keep skin impedance low, the site for electrode placement was prepared by shaving, gently abrading the skin using sandpaper and cleaning with $70 \%$ isopropyl alcohol. Fourteen surface bipolar electrodes $(\mathrm{Ag} / \mathrm{AgCl}$, diameter $8 \mathrm{~mm}$ ) were placed over the bellies of seven muscles from both upper limbs and aligned parallel to muscle fibres in accordance with Seniam's recommendations [61]. The electromyographic signal (EMG) of the following muscles was recorded: Pectoralis major, Deltoideus, Extensor carpi ulnaris, Flexor carpi ulnaris, Triceps brachii, Biceps brachii, Infraspinatus. Again, the suffix '_d' or '_nd' is added to discriminate between dominant versus non-dominant limb, respectively. The EMG signal was recorded using a BrainAmpExG MR system (BrainAmp, BrainProducts, Munich) with a sample frequency of $1000 \mathrm{~Hz}$ and synchronized to the motion capture system using an external trigger.

\subsection{Data processing}

Data processing was conducted using custom Matlab (Mathworks Inc., Novi, USA) routines. Kinematic data were low-pass $(20 \mathrm{~Hz})$ filtered with a second-order Butterworth filter. EMG data were band-pass $(20-500 \mathrm{~Hz})$ filtered with a fourth-order Butterworth filter, rectified to the absolute, and EMG envelopes were obtained using a low-pass $5 \mathrm{~Hz}$ filter [25]. The maximum EMG value of each muscle obtained during the MVCs was used to normalize the EMG recordings (\% MVC). Each trial/session was divided into cycles identified from the vertical displacement of the marker located on the third metacarpal bone (electronic supplementary material, figure S1). Each cycle was intended to detach one flake; there was no preparation of the block toward an ultimate goal that involves a series of cycles related to each other. Therefore, every cycle was accounted for and treated independently. Each cycle was divided into three phases: (i) the analysis phase during which the participant briefly observed and manipulated the block, (ii) the up-swing phase during which he raised his arm and (iii) the down-swing phase during which he executed the strike until the impact of the hammerstone. Technique output (defined here as the percentage of flakes greater than $1.5 \mathrm{~cm}$ out of the total number of strikes) was compared.

Physical demands were assessed by using three criteria: (i) joint excursion, (ii) maximal and (iii) overall muscle solicitations. Joint excursions (for all degrees of freedom) were recorded and compared with published normative data [62]. Maximal muscle solicitation was the peak value of \%MVC and overall muscle solicitation was evaluated using the averaged integrated EMG (iEMG) envelope using the following formula:

$$
\operatorname{iEMG}(x)=\frac{1}{n} \sum_{i=1}^{n} \int_{t_{i}}^{t_{f}} \operatorname{EMG}(t) \mathrm{d} t,
$$

with $x$ the muscle considered, $t_{i}$ and $t_{f}$ the initial and final time of a cycle, $\operatorname{EMG}(t)$ the EMG envelope value at the specific time $t$, and $n$ the number of cycles.

Motor control demands were assessed by using a PCA detailed below. Beforehand, the swing repeatability of standardized cycles was checked using the Sprague and Geers method [63] to ensure representativeness of the mean and for further comparison (electronic supplementary material, table S2).

\subsection{Data analysis and statistics}

The targeted sample size was a minimum of 100 percussive gestures per technique, irrespective of the nature of removals [24]. Given the synchronization issues between motion capture and EMG recordings, some cycles could not be identified for the analysis of muscle activity. Therefore, the analysis of kinematics relies on 138, 120 and 76 strikes for $\mathrm{PH}, \mathrm{BP}$ and $\mathrm{FH}$, respectively; the analysis of muscle activity was performed on 167, 189 and 89 strikes for $\mathrm{PH}, \mathrm{BP}$ and $\mathrm{FH}$.
All data are presented as the mean \pm standard deviation. One-tailed independent $t$-tests were performed to determine the statistical significance of technique output and task economy differences between the three techniques' conditions. The effect size was computed using Cohen's $d$. The following magnitude scale was used for interpretation [64]: less than 0.2, trivial; 0.20.5 , small; $0.5-0.8$, moderate; greater than or equal to 0.8 , large. Statistical significance of averaged iEMG data was tested using an independent two-way ANOVA (with technique and muscle as between-cycles factors).

Statistical parametric mapping (SPM) was used to analyse kinematic and EMG envelopes [65]. SPM analysis was used to identify significant differences between techniques over time. This analysis sets a critical threshold following a random process and computes the $t$ statistic value for each time [66]. When the $t$ value exceeds the threshold, the difference between the two curves is significant. For each technique, one PCA was performed on each cycle to analyse the level of kinematics and muscle intracycle variation. Time (normalized) was set in rows and joint angles/muscle activations were set in columns. The first principal component (PC1) is a measure of task complexity; the smaller the PC1 value, the more complex the task and vice versa [37]. PCAs were based on the covariance matrix in order to keep angles non-normalized [31]. Statistical significance of the variance of the components was tested using one-way independent measure ANOVA. In addition, the contribution of each muscle and each degree of freedom to PC1 was identified by the loading factors that represent the underlying synergy pattern. The standard deviation of the loading factors informs the inter-cycle variation of the movement. For all ANOVAs, when a significant effect was found, Tukey post hoc tests were performed to further identify the origin of statistical differences between conditions. All statistical analyses were conducted using JASP (v.0.10.2) and Matlab (Mathworks Inc., Novi, USA), including the Matlab Toolbox for Dimensionality Reduction [67]. For all statistical tests, significance was set to $p<0.05$.

Before each statistical analysis, the cycles were visually inspected and obvious outliers (manifestly linked to a measurement artefact) dismissed. Considering the high number of observations (greater than 30), the normality distribution was not assessed $[68,69]$ based on the high robustness of the ANOVA against the non-normality of residuals [70,71]. In addition, a Levene test was used to test the homogeneity of the variances. When not met, a permutation ANOVA (lmPerm package for $\mathrm{R}$, the R Core Team, 2020) was performed [72].

\section{Results}

\subsection{Technique output}

No significant difference was found between the output of each technique: the percentage was $25.60 \%$ for $\mathrm{PH}$ (43 flakes out of 168 strikes), $22.30 \%$ for BP ( 66 flakes out of 296 strikes) and $25.8 \%$ for $\mathrm{FH}$ (43 flakes out of 171 strikes). More precisely between PH and BP: $|Z|=0.8053<1.9600, p>0.42$; between $\mathrm{PH}$ and $\mathrm{FH}:|\mathrm{Z}|=0.0950<1.9600, p>0.92$; and between BP and $\mathrm{FH}:|\mathrm{Z}|=0.7012<1.9600, p>0.48$.

\subsection{Physical demands}

\subsubsection{Joint excursion}

There was a significant effect of the technique on the time course of all joint angles and during most of the time (see SPM statistical test results in electronic supplementary material, figure S2). From a general view, the PH technique especially solicited wrist abduction (dominant limb) close to 

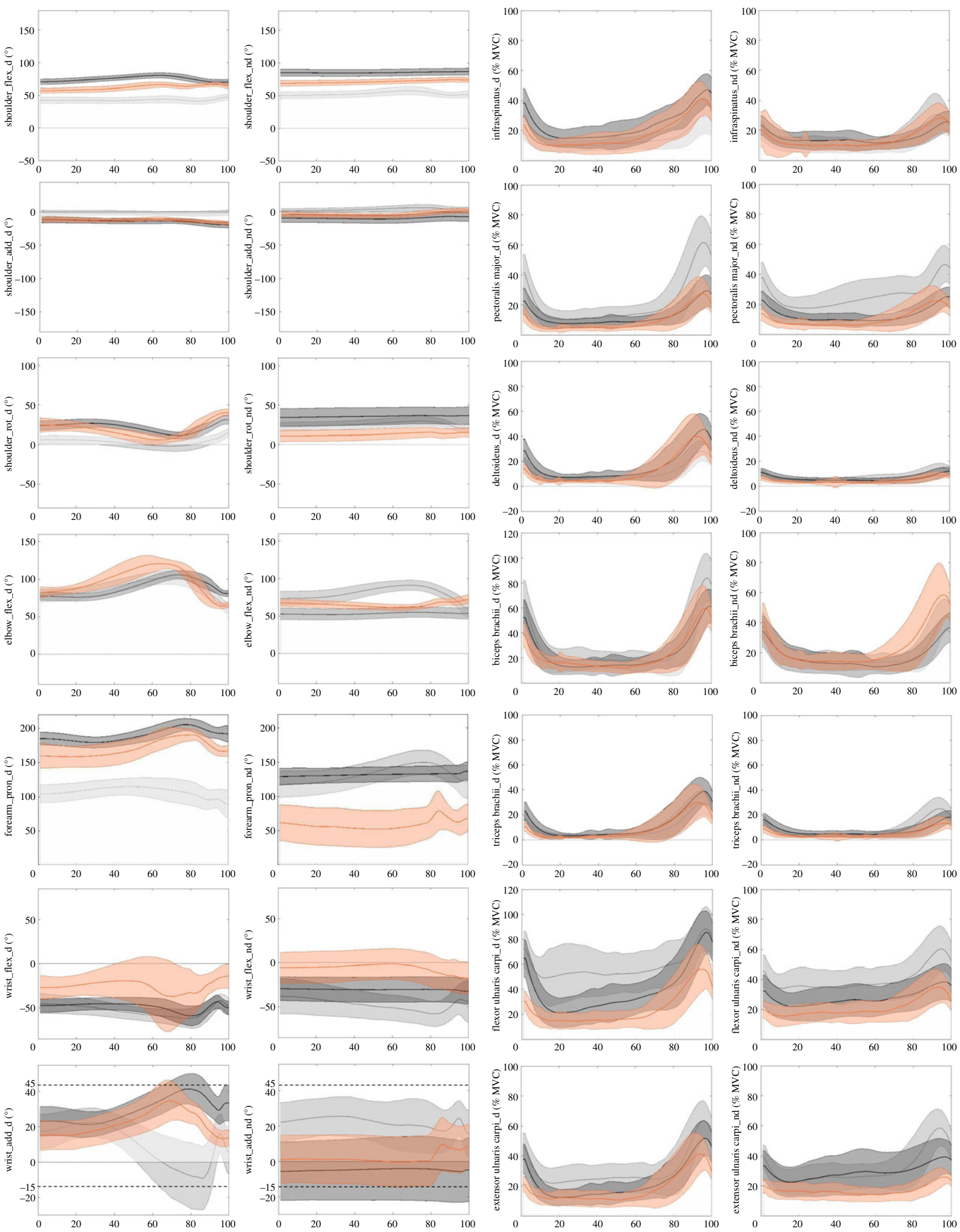

Figure 2. Time courses of joint angles (left) and EMG (right) averaged (with standard deviation) over swing phases and sessions for the three techniques, PH (grey), BP (black) and FH (orange). Joint angle limits according to Kapandji [62].

its theoretical maximal joint range of motion [62]. BP and $\mathrm{FH}$ techniques highly solicited wrist adduction (dominant limb) and abduction (non-dominant limb), as well as forearm pronation (dominant limb) (figure 2, left).

\subsubsection{Maximal muscle solicitation}

There was a significant effect of the technique on muscle activity (see SPM statistical test results in electronic supplementary material, figure S3). For example, the Pectoralis major of the dominant limb exhibited a larger activation peak during the $\mathrm{PH}$ technique than during the other techniques (figure 2, right). Generally, $\mathrm{PH}$ especially solicited Flexor carpi ulnaris and Extensor carpi ulnaris of the nondominant limb, unlike FH and BP. Regardless of the technique, muscles of the dominant limb were generally more solicited than their non-dominant limb homologues especially for Flexor carpi ulnaris and Deltoidus. Biceps brachii 
(a)

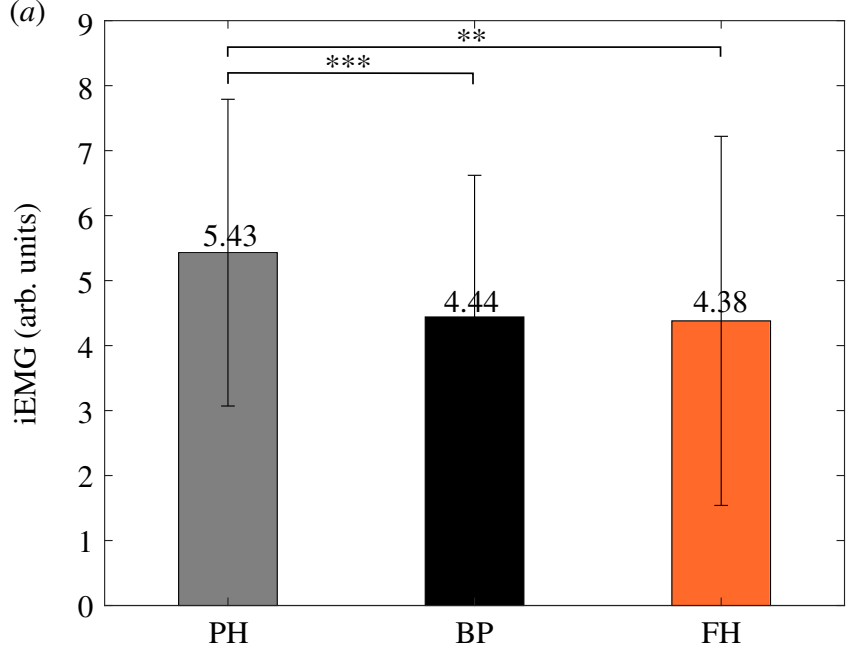

(b)

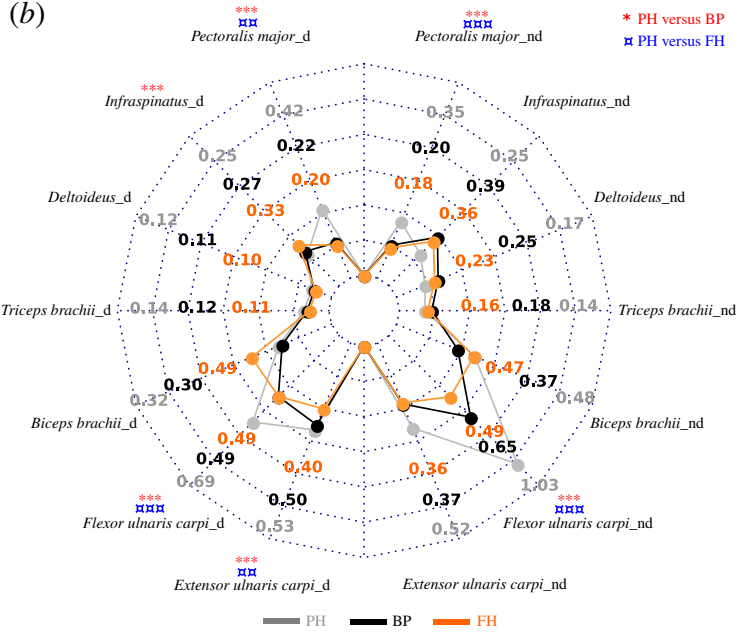

Figure 3. iEMG (expressed in arbitrary units), averaged over cycles and sessions for PH, BP and FH techniques. (a) Sum of all muscles of both limbs. (b) Individual muscle $(n=14)$ solicitation, dominant limb (right-hand side) and non-dominant (left-hand side).

and Flexor carpi ulnaris were the most solicited (up to $80 \%$ of MVC at the time of impact for a few cycles) while Infraspinatus, Deltoideus and Triceps brachii were the least solicited, especially for the non-dominant limb. For all muscles and all techniques, peak activation was observed towards the end of the down-swing phase, around the time of impact.

\subsubsection{Overall muscle solicitation (iEMG)}

In terms of muscle solicitation (figure $3 a)$, $\mathrm{PH}(5.43 \pm 2.36)$ was significantly more demanding than BP $(4.44 \pm 2.18)$ with a difference of $18.3 \%(t=4.10 ; p<0.05 ; d=0.435$, i.e. small effect), and than FH $(4.38 \pm 2.84)$ with a difference of $19.4 \%$ ( $t=2.98 ; p<0.001 ; d=0.393$, i.e. small effect). The permutation ANOVA revealed a significant interaction effect $\left(F_{26,6188}=20.27 ; p<0.001\right)$ of technique on individual muscle demand (figure $3 b$ ). Post hoc analyses revealed a higher demand of $\mathrm{PH}$ over $\mathrm{BP}$ and $\mathrm{FH}$ for the Flexor carpi ulnaris of both limbs (Flexor carpi ulnaris_d: $+28.4 \%$; $t=-13.90 ; p<$ 0.001 and $+29.7 \%$; $t=14.96 ; p<0.001$, respectively, and Flexor carpi ulnaris_nd: $+29.6 \% ; t=6.51 ; p<0.001$ and $+29.6 \%$; $t=5.75 ; p<0.001$, respectively), for the Pectoralis major of both limbs (Pectoralis major_nd: $+48.4 \%$; $t=7.26$; $p<0.001$ and $+52.1 \% ; t=6.31 ; p<0.001$, respectively, and Pectoralis major_d: $+42 \% ; t=5.13 ; p<0.001$ and $+47 \%$; $t=4.70 ; p<0.01$, respectively), and for the Extensor carpi ulnaris of the dominant limb (Extensor carpi ulnaris_d: $+28.4 \% ; t=5.41 ; p<0.001$ and $+29.7 \% ; t=4.58 ; p<0.01$ ). $\mathrm{PH}$ was significantly less demanding than BP for the Infraspinatus of the dominant limb $(-35 \% ; t=5.78 ; p<0.001)$, but not than $\mathrm{FH}(t=3.78 ; p=0.079)$. Also, $\mathrm{FH}$ was significantly more demanding than $\mathrm{PH}$ and $\mathrm{BP}$ for the Biceps brachii of the non-dominant $\operatorname{limb}(+33.8 \% ; t=5.86 ; p<0.001$ and $+38.3 \%$; $t=6.02 ; p<0.01$, respectively).

There was no major difference between the dominant and non-dominant limb as revealed by the vertical axis of symmetry displayed in figure $3 b$ excepted for the Flexor carpi ulnaris for PH which was notably more solicited for the dominant limb. The Triceps brachii was the least solicited muscle for all three techniques while the Flexor carpi ulnaris was the most solicited. In addition, figure $3 b$ illustrates a similar overall pattern between $\mathrm{BP}$ and $\mathrm{FH}$. The main differences between these two techniques are observed for Biceps brachii and the wrist flexor-extensor apparatus. By contrast, $\mathrm{PH}$ differed from the two other techniques by extensive Flexor carpi ulnaris and Pectoralis major demands.

\subsection{Motor control demands}

Joint and muscle coordination was evaluated through PCA as an evaluation of motor control demands.

\subsubsection{Percentage of variance of joint angles and muscle activity accounted for in the first principal component}

As a whole, $\mathrm{FH}$ can be distinguished from $\mathrm{BP}$ and $\mathrm{PH}$ for both kinematics and muscle synergy. In terms of kinematics, there was a significant effect of the technique on the percentage of variance accounted for by PC1 $\left(F_{2,299}=7.962 ; p<\right.$ 0.001) (figure 4). Post hoc revealed that $\mathrm{FH}$ was smaller than BP $(-7.75 \% ; t=-3.860 ; p<0.001 ; d=0.743$, i.e. moderate effect) and $\mathrm{PH}(-7.05 \% ; t=-3.550 ; p=0.001 ; d=-0.591$, i.e. moderate effect). In terms of muscle synergy, there was also a significant effect of the technique on the percentage of variance accounted for by PC1 $\left(F_{2,442}=16.884 ; p<0.001\right)$ (figure 4). Post hoc revealed that $\mathrm{FH}$ was greater than $\mathrm{BP}$ $(+7.47 \% ; t=4.661 ; p<0.001 ; d=0.593$, i.e. moderate effect) and $\mathrm{PH}(+9.31 \% ; t=5.693 ; p<0.001 ; d=0.827$, i.e. large effect).

\subsubsection{Joint and muscle patterns}

The contribution of joint degrees of freedom and muscles to the intra-cycle variance of movement was evaluated through the loading factors of each variable in PC1. In terms of kinematics, no matter the technique, the elbow joint (elbow_flex_d, forearm_pron_d) provided the highest contribution to PC1 for all the techniques. However, these seemed slightly higher for BP and FH techniques. In addition, the wrist contribution (especially in adduction for the dominant limb) was not negligible. Conversely, the shoulder joint was very little solicited, save one exception (Shoulder_rot_d).

In terms of muscle pattern, loading factors were more evenly distributed. Regardless of the technique, Biceps brachii_d and Flexor carpi ulnaris_d were the highest contributing muscles while Deltoideus_nd and Triceps_brachii_nd/d were the smallest. Inter-technique dissimilarities are mainly illustrated by high contributions of Biceps brachii_nd for FH, 
(a)

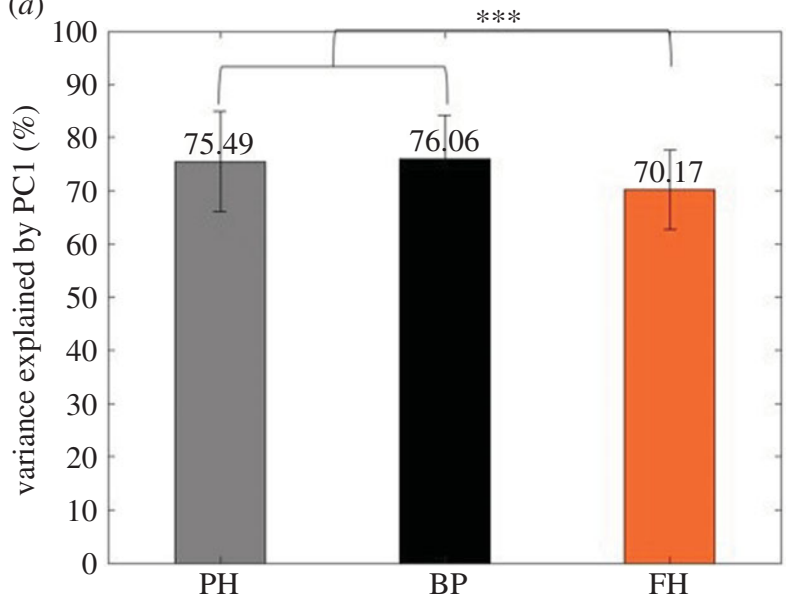

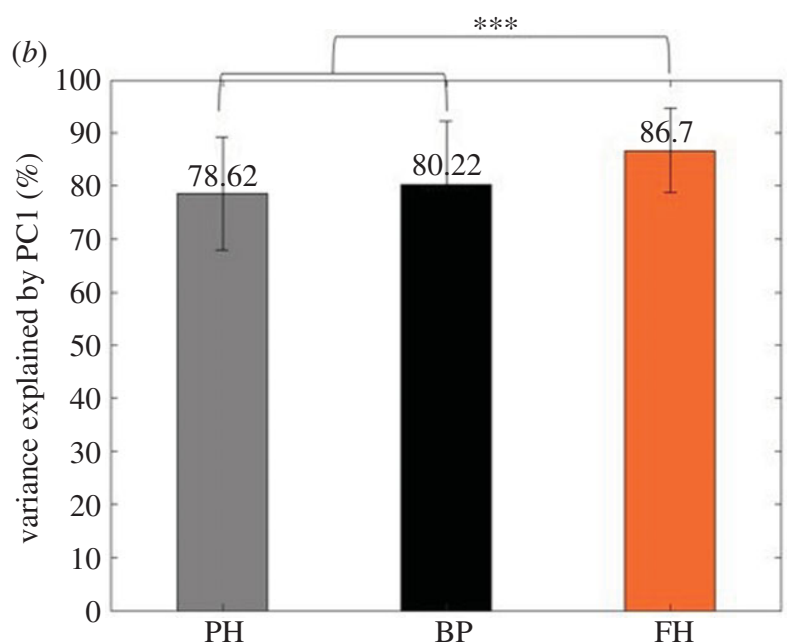

$\mathrm{PH}$

Figure 4. Percentage of variance accounted for by $\mathrm{PC1}$ for each technique (PH, BP and $\mathrm{FH}$ ) in terms of kinematics $(a)$ and muscle activity (b). The $\mathrm{PCAs}$ were performed separately for each technique on all joint angles or muscles, respectively, during the swing phases.

and Pectoralis major_d and Extensor carpi ulnaris_nd for PH figure 5.

\section{Discussion}

This study examined biomechanical and motor control demands associated with flake production processes to shed light into the earliest known stages of hominin technological evolution. We collected kinematics and EMG data from an expert knapper who replicated the earliest known flake production strategies using the three main percussive techniques as currently identified in the Lomekwian and the Oldowan: unipolar flaking on the PH, BP flaking on anvil and multidirectional flaking with FH. This study highlights similarities but also major differences between the three flake production techniques which are discussed below.

\subsection{Technique output}

Whereas Acheulean and other Pleistocene technologies result from a step-by-step implementation to obtain the desired end-product, Lomekwian flake production (and Oldowan to some extent) seem to result from ex tempore operation to obtain sharp edges from a block [44]. Therefore, it was possible to evaluate technique output as the percentage between the number of flakes produced and the number of strikes. As expected by our first hypothesis (H1), our results did not show significant differences between the three analysed percussive techniques. Given the above-mentioned definition of Oldowan and Lomekwian techniques (each strike aims at producing one flake) and the similar output (the same amount of strikes was necessary to produce one flake), each strike can be considered as representative of a technique and then directly comparable. For instance, this would not be the case if a technique would necessitate an average of three strikes to produce one flake while another one would only necessitate one strike.

\subsection{Muscle demands}

In order to assess the energetic cost associated with each strike, we evaluated muscle activity in terms of iEMG. Fourteen main contributor muscles (seven on both limbs) that are recordable using surface electrodes were analysed and results showed that, overall, $\mathrm{PH}$ was approximately $20 \%$ more demanding than $\mathrm{BP}$ an $\mathrm{FH}$. This indicates that the $\mathrm{PH}$ technique requires more energy to produce a flake than the other techniques. This result is in line with our second hypothesis $(\mathrm{H} 2)$, given that the $\mathrm{PH}$ technique involves the manipulation of a heavier stone. Interestingly, $\mathrm{FH}$ is not more demanding than $\mathrm{BP}$, whereas the former technique does not require an anvil but rather the non-dominant hand to stabilize the core. This result underlines the primary stabilizing role of the non-dominant hand whatever the technique [73] and emphasizes the need to investigate the non-dominant limb during stone tool production.

Taken together, results of technique output and economy highlight that a similar number of strikes is needed to detach a flake (one out of four), but $\mathrm{PH}$ still requires more muscle activity than the other two techniques. This has to be put into perspective with the energetic cost associated with locomotion though: even if significant, this discrepancy likely may not have played a critical evolutionary role [74].

A closer look at single muscles' EMG activities (figure 2) revealed that, regardless of the techniques, the most solicited muscles (relative to their maximum potential) were: the wrist flexors-extensors, as previously stressed [11,27,75], and Biceps brachii and Infraspinatus. On the contrary, Deltoideus and Triceps brachii muscle activities were smaller. In terms of inter-technique differences, $\mathrm{PH}$ differs from the other two techniques by higher solicitation of the Pectoralis and wrist flexors/extensors.

The three techniques are associated with similar overall muscle solicitation between the two upper limbs. Such a result is in line with the analysis of Key \& Dunmore [73] that showed that the non-dominant limb is susceptible to experience higher solicitation (in terms of pressure) than the dominant one during Oldowan stone tool reduction. Interestingly, we registered a high solicitation of the nondominant Flexor carpi ulnaris (almost double the value of the dominant side) during the $\mathrm{PH}$ technique. This highlights that besides the apparent symmetry of the bimanual technique, a differential role of the two limbs remains notable.

In evolutionary terms, the particular solicitation of the wrist flexors/extensors, Biceps brachii, and Pectoralis major echoes the archaic (sensu more 'ape-like') morphology of their entheses in the earliest hominins (i.e. Ardipithecus, Australopithecus, Paranthropus and Early Homo as Homo habilis sensu lato and Homo 
(a)

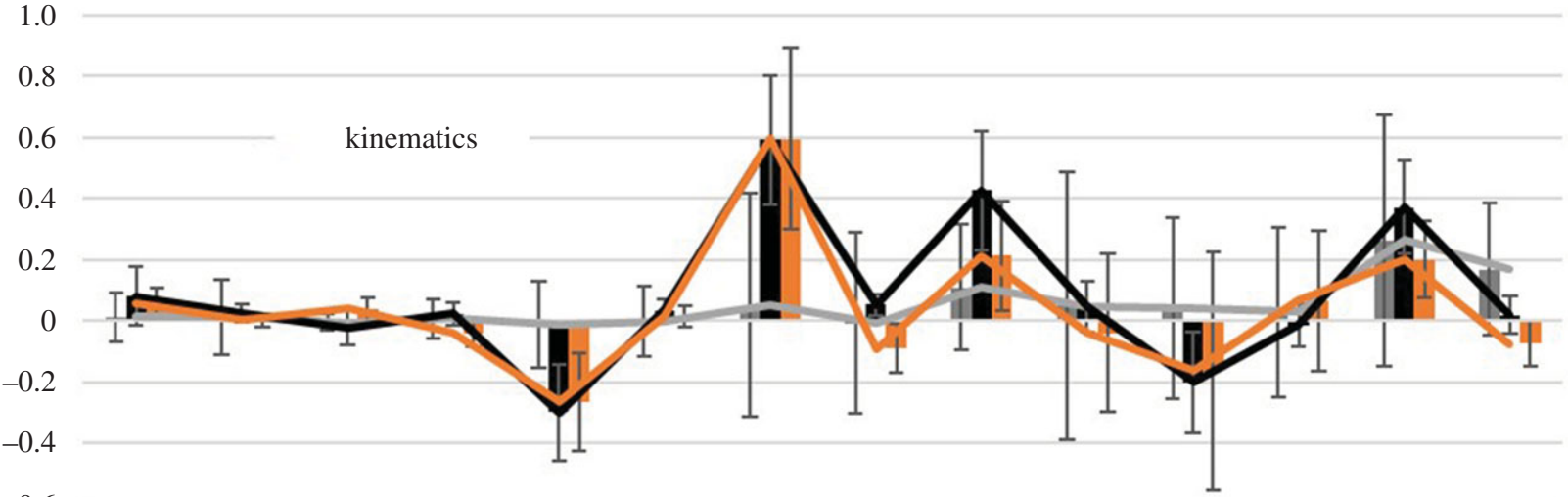

$-0.6$

$-0.8$

$-1.0$

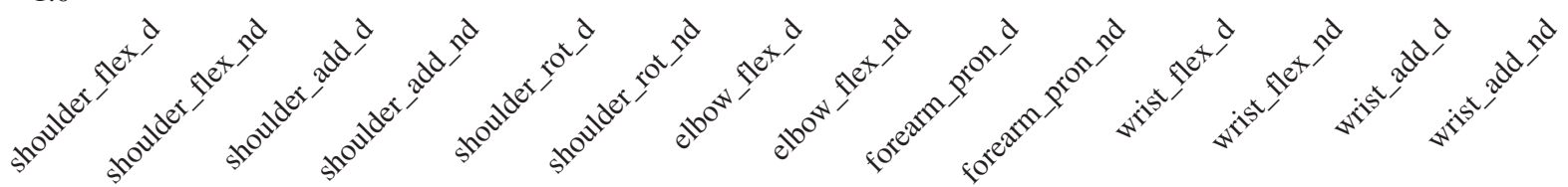

(b)
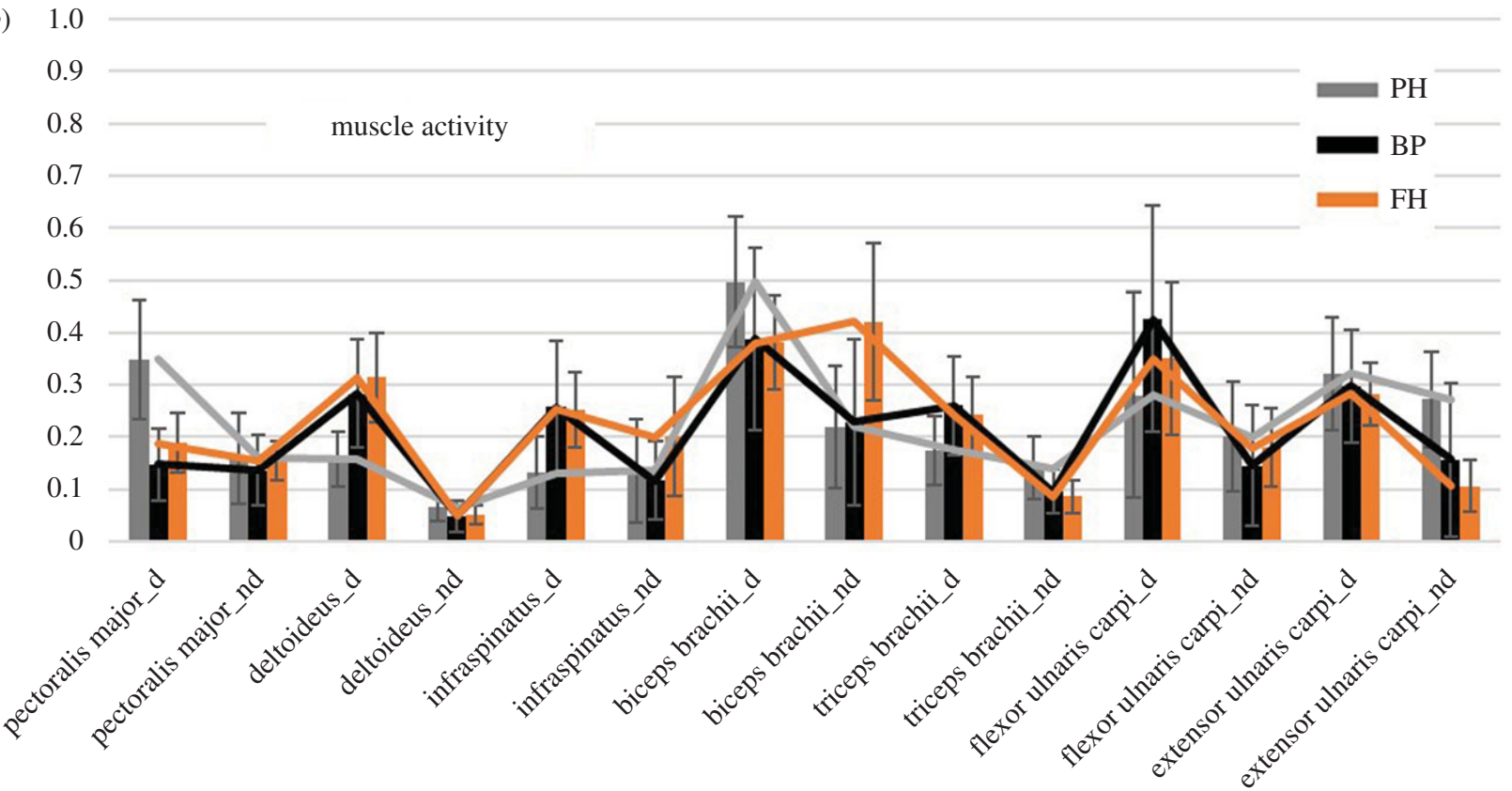

Figure 5. Loading factors of $\mathrm{PC1}$ (contribution to the intra-cycle covariance of movement) averaged over all swing phases derived from joint angle (a) and muscle activity (b) patterns for each technique.

erectus sensu lato) as compared to extant humans [76-78]. Interestingly, this archaic morphology, which may have been primarily promoted by arboreal behaviours, includes a rod-like pisiform, a relatively deep intertubercular groove and a distally located radial enthesis [79-84]. Hence, the hypothesis that nonHomo hominins may have been able to co-opt their archaic morphology to make stone tools (Lomekwian and Oldowan) is reasonable. Otherwise, the differences in muscle solicitation between techniques can be explained by postural differences of the hand. The higher solicitation of the Pectoralis and wrist flexors/extensors typical of $\mathrm{PH}$ is likely due to the manipulation of large-sized stones (mean weight $=3 \mathrm{~kg}$ ) with both hands. Both Deltoideus and Triceps brachii showed very minimal activity in the present study despite their probable functions in humanlike manipulation $[3,85,86]$. Nevertheless, the low contribution of those muscles could be explained by the fact that the expert mostly solicited the heads of those muscles that were not monitored by the electrodes.

\subsection{Joint excursion}

Overall, based on the joint limits reported by Kapandji [62], the visualization of kinematic curves (figure 2) showed neither substantial excursion nor extreme positions at the shoulder joint during our stone tool production experiments. In other words, for all the techniques, achieving the speed of the endpoint effector (i.e. the hand) necessary to detach a flake did not require a great range of motion of the shoulder. From an evolutionary perspective, this tends to indicate that mobility of the shoulder joint complex would have played little role in the evolution of percussive techniques. 
The greater joint excursion was observed for the elbow/ forearm and wrist joints that reached or even exceeded their theoretical joint boundaries provided by Kapandji [62]. This result concerned wrist abduction/adduction and forearm pronation. Exceeding theoretical joint boundaries has to be put into perspective, as those limits are indicative and not specific to the participant. Still, BP and FH necessitated a greater amount of forearm pronation than $\mathrm{PH}$. Therefore, it could be hypothesized that limited pronation capabilities would prevent using BP and FH techniques while 'individuals' with such a limitation would easier use the $\mathrm{PH}$ technique. Thus, regarding the overall small joint excursions of $\mathrm{PH}$ our third hypothesis was validated.

Great changes in wrist flexion/extension and adduction/ abduction were observed during the down-swing, indicating a large joint angular velocity that serves in accelerating the core as previously observed [27]. As expected, the nondominant limb exhibited larger joint excursions for $\mathrm{PH}$ than for $\mathrm{BP}$ and $\mathrm{FH}$, the latter two in which the limb mainly remains immobile to maintain the core. Nonetheless, joint excursions were not symmetrical, even if, a priori, the movement may resemble a simple bimanual task. For example, wrist adduction was more solicited for the dominant limb than for the non-dominant limb and conversely for forearm pronation. The relatively high standard deviation observed for the forearm and wrist joint would underline their importance in the modulation of the movement. This question was addressed thoroughly through the analysis of the motor control demands associated with each technique.

\subsection{Motor control demands}

Stone tool production has been linked to cognitive and motor skill evolution, in particular the idea that the transition from anvil and hammer percussive techniques to freehand knapping techniques in early hominins would have necessitated improved motor control superior to that of non-human primates [87]. We compared techniques' complexity in terms of control strategies involved in the processes, at the level of both kinematic and muscle activity patterns. More specifically, we used PCA to report variance accounted for by PC1 as it significantly depends on the conditions of the motor task and therefore can be interpreted as a measure of the complexity of movement control for the CNS [37].

Overall, our PCA revealed that a high percentage of variance $(70-85 \%)$ was explained by PC1, for both kinematics and muscle activity. This indicates that intra-cycle fluctuations can predominantly be represented by a single synergy and argues in favour of stone knapping being a highly coordinated movement. Faisal et al. [43] used PCA to investigate the complexity of grip patterns in the supporting hand during Oldowan and Acheulean stone knapping in one modern expert knapper. Analysis of the fingers' joint angles showed that PC1 accounted for only $25-40 \%$ of the variance in the data and five strategies (PC1-PC5) were needed to explain $85 \%$ of the variance. They also indicated no significant differences between Oldowan and Acheulean toolmaking in grip pattern complexity. Biryukova \& Bril [31], who investigated arm segment kinematics of the striking arm in stone bead knapping among Indian workers, used a similar approach. They reported that PC1 accounted for $79-98 \%$ of the variation in joint angle data. They also found a negative relationship between level of expertise and percentage of variance accounted for by PC1. Based on these two studies we hypothesized (H4) that the percentage of covariance accounted for by PC1 would be greater in the $\mathrm{PH}$ technique than in the other techniques, thus revealing a less complex technique. Our study partially invalidates this hypothesis as there was no significant difference between $\mathrm{PH}$ and $\mathrm{BP}$, in terms of both kinematics and muscle activity. Nonetheless, FH was distinguished from the other two: for kinematics, PC1 was lower (70\%) than BP and $\mathrm{PH}$ (both approx. 75\%). This result tends to indicate that $\mathrm{BP}$ and $\mathrm{PH}$ share the same level of complexity while, given the smaller part of variance accounted by the first synergy in $\mathrm{FH}$, the later technique would be more complex. This difference in kinematic strategies is not corroborated by the intra-cycle variation of EMG as PC1 was higher for $\mathrm{FH}$ than for $\mathrm{BP}$ and $\mathrm{PH}$, this time indicating a less complex task from a muscle activation strategy point of view.

If a definitive and comprehensive answer to this apparent discrepancy between kinematic and muscle activation strategies remains to be explained, a few elements are presented. First, we found that regardless of the technique, the percentage of variance explained by $\mathrm{PC} 1$ was higher for muscle activity than for kinematics. The percentage of variance explained depends on the numbers of degrees of freedom accounted for by the regression model (i.e. the loading factors). We analysed 14 kinematic degrees of freedom and 14 muscles; therefore, this cannot be an explanation in our study. An identical result was previously reported by Tagliabue et al. [88] who argued that this may reflect the higher degree of motor redundancy compared to kinematic redundancy, even if all muscles acting during the movement were not recorded [89]. Tagliabue et al. [88] hypothesized that muscle synergies are thus only partially at the source of kinematic synergies. One evident illustration is that muscle activity and kinematics are totally dissociated under strict isometric conditions. The higher contribution of Biceps brachii in the FH technique over $\mathrm{PH}$ and BP is especially remarkable for the non-striking limb. This result highlights the essential role of the non-dominant/supportive limb in the evolution of stone tool knapping, as previously stressed [73,90]. Lastly, a closer look at loading factors shows that, compared to the wrist and elbow-forearm, the shoulder accounted for little variance in the kinematics strategy revealed by PC1, in line with the limited mobility reported in the analysis of joint excursion. The elbow joint played a greater role in the strategy than the wrist joint, as previously reported [90].

In an evolutionary perspective, analyses of motor control demands emphasize that $\mathrm{FH}$ is more complex than $\mathrm{PH}$ and $\mathrm{BP}$ in terms of joint angle synergies but less complex in terms of muscle synergies, partially invalidating our fourth hypothesis (H4). Interestingly, FH greater distinguished from the two other techniques. This may indicate that the transition from anvil and hammer percussive techniques (PH and $\mathrm{BP}$ ) to freehand knapping techniques (FH) would have been associated with better motor control. This better motor control may have originated from the acquisition of a behavioural repertoire that gradually formed an evolutionary advantage for dissociated bimanual limb movements in general and stone tool production in particular [90]. Task complexity and motor control demands are multifactorial, and their analysis remains an ongoing concern [31,37]. Variance accounted for by $\mathrm{PC} 1$ is an indicator among 
others, and further studies using complementary approaches are needed to get a more comprehensive view on this point.

\subsection{Limitations}

Some limitations are acknowledged. Limitations typically associated with marker-based motion analysis and surface electromyography apply. More specifically, joint angles results depend on the kinematic model used and may be affected by simplification, especially at the shoulder level. Muscle demand results are inevitably sensitive to the EMG normalization process based on MVC that relies on individual will and the posture retained by experimenters. This study investigated muscle and kinematic demands of a single knapper. Even if we report high degree of intraindividual repeatability, the results of this study would need to be reinforced by including a panel of experts to ensure that our main conclusions withstand the interindividual variation, especially from an anatomical point of view [26]. The recruitment of experts would necessitate a long-time training period for them to master the replication of the three techniques of interest here [48-50]. Our findings are based on a modern human morphology that significantly differs from fossil hominins. Modern humans remain the best extant analogue [91] for experimental studies, but biomechanical simulation could help to further address the influence of musculoskeletal variation such as bone morphology and muscle attachment sites $[10,12,47]$. This study aimed at considering the overall musculature and mobility of the upper limb at three joints (wrist, elbow and shoulder) in an evolutionary perspective. Similarly, additional biomechanical analyses focused on the hand should be of prime interest since this anatomical complex was intensively studied in the frame of stone tool use and making. In line with this limit, the synergies being dependent on the number of variables included in the matrix, additional muscles or joint angles may marginally alter our findings. Each cycle was considered independent and unrelated to another [43,44]; considering that physical demands and synergies may still be influenced by the varying size and shape all along the replication session, this assumption should be addressed through an additional dedicated study.

Ethics. The participant in this study gave his written informed consent under guidelines of the local research ethics committee and the protocole was carried out in compliance with the Helsinki Declaration. Data accessibility. Data are available from Dryad: https://doi.org/10. 5061/dryad.cfxpnvx51 [92]. Code can be downloaded from: https://github.com/mdomalai/BiomechStoneToolmaking_RSI. The data are provided in the electronic supplementary material.

Authors' contributions. G.D. and M.D. designed the study/experiments. R.M. wrote the original manuscript. S.H., J.L. M.B. and S.P. collected the raw material from the field. M.B. made the stone tool replications. L.H. and M.D. collected the data. R.M. and M.D. made the analyses. All authors contributed in the interpretation and edited the manuscript. All authors gave final approval for publication and agree to be held accountable for the work performed therein.

Competing interests. We declare we have no competing interests.

Funding. This work was supported by the Agence Nationale de la Recherche (grant nos. ANR-12-CULT-0006 and ANR-17-CE27-0005), Région Nouvelle Aquitaine (grant no. CPER-FEDER P-2017-BAFE68), in partnership with the European Union (FEDER/ERDF, European Regional Development Fund).

Acknowledgement. This work benefited from the support of several institutions and colleagues we wish to acknowledge here. We are particularly indebted to the Mission Préhistorique au Kenya/West Turkana Archaeological Project for providing the raw materials for the experiments, and the Turkana Basin Institute for logistical assistance. The Mission Préhistorique au Kenya/West Turkana Archaeological Project is funded by the French Ministry of Europe and Foreign Affairs (Nu681/DGM/ATT/RECH, Nu986/DGM/ DPR/PRG). We thank the Kenyan authorities for permission to conduct research in the field: the Office of the President of Kenya, the Ministry of Education, Science and Technology of the Republic of Kenya, the National Council for Science and Technology (NACOSTI/P/19/9889/31099) and the National Museums of Kenya. We are very grateful to $\mathrm{H}$. Roche for her help and interactive discussions at the initiation of this project. We also thank G. Reynaud (UMR7262) and P. Boston (UMR7194) for administrative guidance. The authors thank the excavators of the WTAP for their hard work in the field as well as the Turkana communities for field assistance.

\section{References}

1. Villmoare B, Kimbel WH, Seyoum C, Campisano CJ, DiMaggio EN, Rowan J, Braun DR, Arrowsmith JR, Reed KE. 2015 Early Homo at $2.8 \mathrm{Ma}$ from LediGeraru, Afar, Ethiopia. Science 347, 1352-1355. (doi:10.1126/science.aaa1343)

2. Leakey LSB, Tobias PV, Napier JR. 1964 A new species of the genus homo from Olduvai Gorge. Nature 202, 7-9. (doi:10.1038/ 202007a0)

3. Drapeau MSM. 2012 Forelimb adaptations in Australopithecus afarensis. In African genesis: perspectives on hominin evolution (eds A Gallagher, SC Reynolds), pp. 223-247. Cambridge, UK: Cambridge University Press.

4. Marzke MW. 2013 Tool making, hand morphology and fossil hominins. Phil. Trans. R Soc. B 368, 20120414. (doi:10.1098/rstb.2012. 0414)

5. Kivell TL. 2015 Evidence in hand: recent discoveries and the early evolution of human manual manipulation. Phil. Trans. R. Soc. B 370, 20150105. (doi:10.1098/rstb.2015.0105)

6. Alba DM, Moyà-Solà S, Köhler M. 2003 Morphological affinities of the Australopithecus afarensis hand on the basis of manual proportions and relative thumb length. J. Hum. Evol. 44, 225-254. (doi:10.1016/500472484(02)00207-5)

7. Marzke MW. 1983 Joint functions and grips of the Australopithecus afarensis hand, with special reference to the region of the capitate. J. Hum. Evol. 12, 197-211. (doi:10.1016/500472484(83)80025-6)

8. Marzke MW. 1997 Precision grips, hand morphology, and tools. Am. J. Phys. Anthropol. 102, 91-110. (doi:10.1002/(SICI)1096-8644(199701) 102:1<91::AID-AJPA8>3.0.C0;2-G)

9. Tocheri MW, Marzke MW, Liu D, Bae M, Jones GP, Williams RC, Razdan A. 2003 Functional capabilities of modern and fossil hominid hands: three- dimensional analysis of trapezia. Am. J. Phys. Anthropol. 122, 101-112. (doi:10.1002/ajpa.10235)

10. Feix T, Kivell TL, Pouydebat E, Dollar AM. 2015 Estimating thumb-index finger precision grip and manipulation potential in extant and fossil primates. J. R. Soc. Interface 12, 20150176. (doi:10. 1098/rsif.2015.0176)

11. Bardo A, Vigouroux L, Kivell TL, Pouydebat E. 2018 The impact of hand proportions on tool grip abilities in humans, great apes and fossil hominins: a biomechanical analysis using musculoskeletal simulation. J. Hum. Evol. 125, 106-121. (doi:10. 1016/j.jhevol.2018.10.001)

12. Domalain M, Bertin A, Daver G. 2017 Was Australopithecus afarensis able to make the Lomekwian stone tools? Towards a realistic biomechanical simulation of hand force capability in fossil hominins and new insights on the role of the fifth digit. C.R. Palevol 16, 572-584. (doi:10.1016/ j.crpv.2016.09.003) 
13. de Heinzelin J, Clark JD, White T, Hart W, Renne P, WoldeGabriel G, Beyene Y, Vrba E. 1999 Environment and behavior of 2.5-million-year-old Bouri hominids. Science 284, 625-629. (doi:10. 1126/science.284.5414.625)

14. McPherron SP, Alemseged Z, Marean CW, Wynn JG, Reed D, Geraads D, Bobe R, Béarat HA. 2010 Evidence for stone-tool-assisted consumption of animal tissues before 3.39 million years ago at Dikika, Ethiopia. Nature 466, 857-860. (doi:10. 1038/nature09248)

15. Domínguez-Rodrigo M, Pickering TR, Bunn HT. 2011 Reply to McPherron et al.: doubting Dikika is about data, not paradigms. Proc. Natl Acad. Sci. USA 108, E117. (doi:10.1073/pnas.1104647108)

16. Harmand $S$ et al. 2015 3.3-million-year-old stone tools from Lomekwi 3, West Turkana, Kenya. Nature 521, 310-315. (doi:10.1038/nature 14464)

17. Archer W, Aldeias V, McPherron SP. 2020 What is 'in situ'? A reply to Harmand et al. (2015). J. Hum. Evol. 142, 102740. (doi:10.1016/j.jhevol.2020. 102740)

18. Lewis JE, Harmand S. 2016 An earlier origin for stone tool making: implications for cognitive evolution and the transition to Homo. Phil. Trans. R. Soc. B 371, 20150233. (doi:10.1098/rstb. 2015.0233)

19. Crabtree DE. 1970 An introduction to flintworking, 1st edn. Pocatello, ID: Idaho State University Museum.

20. Mourre V, Villa P, Henshilwood CS. 2010 Early use of pressure flaking on lithic artifacts at Blombos Cave, South Africa. Science 330, 659-662. (doi:10. 1126/science.1195550)

21. Boesch C, Boesch PC, Boesch-Achermann H. 2000 The chimpanzees of the Tai forest: behavioural ecology and evolution. Oxford, UK: Oxford University Press.

22. Liu $Q$, Simpson $K$, Izar $P$, Ottoni E, Visalberghi E, Fragaszy D. 2009 Kinematics and energetics of nutcracking in wild capuchin monkeys (Cebus libidinosus) in Piauí, Brazil. Am. J. Phys. Anthropol. 138, 210-220. (doi:10.1002/ajpa.20920)

23. Gumert MD, Kluck M, Malaivijitnond S. 2009 The physical characteristics and usage patterns of stone axe and pounding hammers used by long-tailed macaques in the Andaman Sea region of Thailand. Am. J. Primatol. 71, 594-608. (doi:10.1002/ajp. 20694)

24. Williams EM, Gordon AD, Richmond BG. 2014 Biomechanical strategies for accuracy and force generation during stone tool production. J. Hum. Evol. 72, 52-63. (doi:10.1016/j.jhevol.2014.03.004)

25. Feuerriegel E. 2016 Biomechanics of the Hominin Upper Limb: Entheseal Development and Stone Tool Manufacture. See https://openresearch-repository. anu.edu.au/handle/1885/118236.

26. Marzke MW, Toth N, Schick K, Reece S, Steinberg B, Hunt K, Linscheid RL, An KN. 1998 EMG study of hand muscle recruitment during hard hammer percussion manufacture of Oldowan tools. Am. J. Phys. Anthropol. 105, 315-332. (doi:10.

1002/(SICI)1096-8644(199803)105:3<315::AID-

AJPA3>3.0.(0;2-0)

27. Williams EM, Gordon AD, Richmond BG. 2010 Upper limb kinematics and the role of the wrist during stone tool production. Am. J. Phys. Anthropol. 143, 134-145. (doi:10.1002/ajpa.21302)

28. Latash ML, Anson JG. 2006 Synergies in health and disease: relations to adaptive changes in motor coordination. Phys. Ther. 86, 1151-1160. (doi:10. 1093/ptj/86.8.1151)

29. Parry R, Dietrich G, Bril B. 2014 Tool use ability depends on understanding of functional dynamics and not specific joint contribution profiles. Front. Psychol. 5, 306. (doi:10.3389/fpsyg.2014.00306)

30. Santello M, Flanders M, Soechting JF. 2002 Patterns of hand motion during grasping and the influence of sensory guidance. J. Neurosci. 22, 1426-1435. (doi:10.1523/JNEUROSCI.22-04-01426.2002)

31. Biryukova EV, Bril B. 2008 Organization of goaldirected action at a high level of motor skill: the case of stone knapping in India. Motor Control 12, 181-209. (doi:10.1123/mcj.12.3.181)

32. Brochier T, Spinks RL, Umilta MA, Lemon RN. 2004 Patterns of muscle activity underlying object-specific grasp by the macaque monkey. J. Neurophysiol. 92, 1770-1782. (doi:10.1152/jn.00976.2003)

33. Rearick MP, Casares A, Santello M. 2003 Taskdependent modulation of multi-digit force coordination patterns. J. Neurophysiol. 89, 1317-1326. (doi:10.1152/jn.00581. 2002)

34. Karakostis FA, Hotz G, Tourloukis V, Harvati K. 2018 Evidence for precision grasping in Neandertal daily activities. Sci. Adv. 4, eaat2369. (doi:10.1126/sciadv. aat2369)

35. Karakostis FA, Hotz $G$, Scherf $H$, Wahl J, Harvati K. 2017 Occupational manual activity is reflected on the patterns among hand entheses. Am. J. Phys. Anthropol. 164, 30-40. (doi:10.1002/ ajpa.23253)

36. Karakostis FA, Reyes-Centeno H, Franken M, Hotz G, Rademaker K, Harvati K. 2021 Biocultural evidence of precise manual activities in an Early Holocene individual of the high-altitude Peruvian Andes. Am. J. Phys. Anthropol. 174, 35-48. (doi:10.1002/ ajpa.24160)

37. Gorkovenko AV, Lehedza OV, Abramovych TI, Pilewska W, Mischenko VS, Zasada M. 2019 Evaluation of the complexity of control of simple linear hand movements using principal component analysis. Neurophysiology 51, 132-140. (doi:10. 1007/s11062-019-09804-w)

38. Bril B, Smaers J, Steele J, Rein R, Nonaka T, Dietrich G, Biryukova E, Hirata S, Roux V. 2012 Functional mastery of percussive technology in nut-cracking and stone-flaking actions: experimental comparison and implications for the evolution of the human brain. Phil. Trans. R. Soc. B 367, 59-74. (doi:10. 1098/rstb.2011.0147)

39. Morgan TJH et al. 2015 Experimental evidence for the co-evolution of hominin tool-making teaching and language. Nat. Commun. 6, 6029. (doi:10.1038/ ncomms7029)
40. Bril B, Parry R, Dietrich G. 2015 How similar are nut-cracking and stone-flaking? A functional approach to percussive technology. Phil. Trans. $R$. Soc. B 370, 20140355. (doi:10.1098/rstb.2014.0355)

41. Bril B, Roux V (eds). 2005 Stone knapping: the necessary conditions for a uniquely hominin behaviour. Cambridge, UK: MCDonald Institute for Archaeological Research.

42. Stout D, Chaminade T. 2007 The evolutionary neuroscience of tool making. Neuropsychologia 45, 1091-1100. (doi:10.1016/j.neuropsychologia.2006. 09.014)

43. Faisal A, Stout D, Apel J, Bradley B. 2010 The manipulative complexity of lower Paleolithic stone toolmaking. PLOS ONE 5, e13718. (doi:10.1371/ journal.pone.0013718)

44. Stout D. 2011 Stone toolmaking and the evolution of human culture and cognition. Phil. Trans. R. Soc. B 366, 1050-1059. (doi:10.1098/rstb.2010.0369)

45. Galletta L, Stephens NB, Bardo A, Kivell TL, Marchi D. 2019 Three-dimensional geometric morphometric analysis of the first metacarpal distal articular surface in humans, great apes and fossil hominins. J. Hum. Evol. 132, 119-136. (doi:10.1016/j.jhevol. 2019.04.008)

46. Marzke MW, Tocheri MW, Steinberg B, Femiani JD, Reece SP, Linscheid RL, Orr CM, Marzke RF. 2010 Comparative $3 \mathrm{D}$ quantitative analyses of trapeziometacarpal joint surface curvatures among living catarrhines and fossil hominins. Am. J. Phys. Anthropol. 141, 38-51. (doi:10.1002/ ajpa.21112)

47. Karakostis FA, Haeufle D, Anastopoulou I, Moraitis K, Hotz G, Tourloukis V, Harvati K. 2021 Biomechanics of the human thumb and the evolution of dexterity. Curr. Biol. 31, 1317-1325.e8. (doi:10.1016/j.cub. 2020.12.041)

48. Bourguignon $L$, Brenet $M$, Folgado $M$, EXARC Experimental Archaeology Collection Manager. 2011 Approche expérimentale de la variabilité des industries du Paléolithique moyen: I'intérêt d'évaluer les niveaux compétence des expérimentateurs. Experimentación en arqueología: estudio y difusión del pasado 25, 177-182.

49. Torres C, Preysler JB. 2020 Experts also fail: a new methodological approach to skills analysis in lithic industries. J. Paleolit. Archaeol. 3, 889-917. (doi:10. 1007/541982-020-00063-4)

50. Khreisheh NN. 2013 The acquisition of skill in early flaked stone technologies: an experimental study. PhD thesis, University of Exeter. See https://ore. exeter.ac.uk/repository/handle/10871/14986.

51. Harmand S. 2009 Variability in raw material selectivity at the Late Pliocene sites of Lokalalei, West Turkana, Kenya. In Interdisciplinary approaches to the Oldowan (eds E Hovers, DR Braun), pp. 85-97. Dordrecht, The Netherlands: Springer.

52. Harmand S. 2009 Raw materials and technoeconomic behaviors at Oldowan and Acheulean sites in the West Turkana Region, Kenya. In Lithic materials and Paleolithic societies (eds B Adams, BS Blades), pp. 1-14. Chichester, UK: Wiley-Blackwell. (doi:10.1002/9781444311976.ch1) 
53. Stout D. 2002 Skill and cognition in stone tool production: an ethnographic case study from Irian Jaya. Curr. Anthropol. 43, 693-722. (doi:10. 1086/342638)

54. Short RV. 1979 Sexual selection and its component parts, somatic and genital selection, as illustrated by man and the great apes. In Advances in the study of behavior (eds JS Rosenblatt, RA Hinde, ( Beer, M-C Busnel), pp. 131-158. New York, NY: Academic Press.

55. Boesch C, Boesch H. 1984 Possible causes of sex differences in the use of natural hammers by wild chimpanzees. J. Hum. Evol. 13, 415-440. (doi:10. 1016/S0047-2484(84)80055-X)

56. Blache $Y$, Desmoulins $L$, Allard $P$, Plamondon A, Begon M. 2015 Effects of height and load weight on shoulder muscle work during overhead lifting task. Ergonomics 58, 748-761. (doi:10.1080/ 00140139.2014.980336)

57. Jackson M, Michaud B, Tétreault P, Begon M. 2012 Improvements in measuring shoulder joint kinematics. J. Biomech. 45, 2180-2183. (doi:10. 1016/j.jbiomech.2012.05.042)

58. Michaud B, Duprey S, Begon M. 2017 Scapular kinematic reconstruction - segmental optimization, multibody optimization with open-loop or closed-loop chains: which one should be preferred? Int. Biomech. 4, 86-94. (doi:10.1080/23335432. 2017.1405741)

59. Delp SL, Anderson FC, Arnold AS, Loan P, Habib A, John CT, Guendelman E, Thelen DG. 2007 OpenSim: open-source software to create and analyze dynamic simulations of movement. IEEE Trans. Biomed. Eng. 54, 1940-1950. (doi:10.1109/TBME. 2007.901024)

60. Rajagopal A, Dembia CL, DeMers MS, Delp DD, Hicks JL, Delp SL. 2016 Full-body musculoskeletal model for muscle-driven simulation of human gait. IEEE Trans. Biomed. Eng. 63, 2068-2079. (doi:10.1109/ TBME.2016.2586891)

61. Hermens HJ, Freriks B, Disselhorst-Klug C, Rau G. 2000 Development of recommendations for SEMG sensors and sensor placement procedures. J. Electromyogr. Kinesiol. 10, 361-374. (doi:10. 1016/s1050-6411(00)00027-4)

62. Kapandji A-I. 1970 Physiologie articulaire 1. Membre supérieur, 5e édn. Paris, France: Maloine.

63. Ray MH, Mongiardini M, Plaxico C. 2012 Quantitative methods for assessing similarity between computational results and full-scale crash tests. Transportation Research Board 91st Annual Meeting, Washington, DC, USA, 22-26 January 2012.

64. Cohen J. 1988 Statistical power analysis for the behavioral sciences. Hillsdale, NJ: L. Erlbaum Associates.

65. Penny WD, Friston KJ, Ashburner JT, Kiebel SJ, Nichols TE. 2006 Statistical parametric mapping: the analysis of functional brain images, 1st edn. Amsterdam, the netherlands: Academic Press Inc.

66. Pataky TC, Vanrenterghem J, Robinson MA. 2015 Zero- vs. one-dimensional, parametric vs. nonparametric, and confidence interval vs. hypothesis testing procedures in one-dimensional biomechanical trajectory analysis. J. Biomech. $\mathbf{4 8}$, 1277-1285. (doi:10.1016/j.jbiomech.2015.02.051)

67. van der Maaten LVD. 2015 Matlab toolbox for dimensionality reduction. See http://homepage. tudelft.nl/19j49/MatlabToolboxforDimensionality Reduction.html (accessed 7 January 2015).

68. Pallant J. 2003 SPSS survival manual: a step-by-step guide to data analysis using SPSS for windows (versions 10 and 11). Buckingham, UK: Open University Press.

69. Elliott AC, Woodward WA. 2006 Statistical analysis quick reference guidebook: with SPSS examples. Thousand Oaks, CA: SAGE Publications.

70. Ito PK. 19807 Robustness of ANOVA and MANOVA test procedures. In Handbook of statistics, pp. 199-236. Amsterdam, The Netherlands: Elsevier.

71. Schmider E, Ziegler M, Danay E, Beyer L, Bühner M. 2010 Is it really robust? Methodology 6, 147-151. (doi:10.1027/1614-2241/a000016)

72. Mendes M, Akkartal E. 2009 Comparison of ANOVA F and WELCH tests with their respective permutation versions in terms of type I error rates and test power. Kafkas Univ. Vet. Fak. Derg. 16, 711-716. (doi:10.9775/kvfd.2009.1507)

73. Key AJM, Dunmore C. 2015 The evolution of the hominin thumb and the influence exerted by the non-dominant hand during stone tool production. J. Hum. Evol. 78, 60-69. (doi:10.1016/j.jhevol.2014. 08.006)

74. Sockol MD, Raichlen DA, Pontzer H. 2007 Chimpanzee locomotor energetics and the origin of human bipedalism. Proc. Natl Acad. Sci. USA 104, 12 265-12 269. (doi:10.1073/pnas.0703267104)

75. Feuerriegel EM, Halaki M, Reed D, Groves CP, Ginn KA. 2017 Electromyography, kinematics, and kinetics of the upper limb during Oldowan stone tool manufacture. 86th Annual Meeting of American Association of Physical Anthropologists, New Orleans, LA, USA, 19-22 April 2017.

76. Senut B. 1991 Forme et mouvement chez des primates néogènes de l'ancien monde. Geobios 24, 193-199. (doi:10.1016/50016-6995(66)80024-4)

77. Susman RL, de Ruiter D, Brain CK. 2001 Recently identified postcranial remains of Paranthropus and Early Homo from Swartkrans Cave, South Africa. J. Hum. Evol. 41, 607-629. (doi:10.1006/jhev.2001.0510)

78. Daver $\mathrm{G}$ et al. $2018 \mathrm{New}$ hominin postcranial remains from locality $0 \mathrm{MO} 323$, Shungura Formation, Lower Omo Valley, southwestern Ethiopia. J. Hum. Evol. 122, 23-32. (doi:10.1016/j.jhevol.2018.03.011)
79. Lague MR. 2014 The pattern of hominin postcranial evolution reconsidered in light of size-related shape variation of the distal humerus. J. Hum. Evol. 75, 90-109. (doi:10.1016/j.jhevol.2014.07.003)

80. Stern JT, Susman RL. 1983 The locomotor anatomy of Australopithecus afarensis. Am. J. Phys. Anthropol. 60, 279-317. (doi:10.1002/ajpa.1330600302)

81. Jouffroy F. 1991 La 'main sans talon' du primate bipède. In Origine(s) de la bipddie chez les hominidés (eds $Y$ Coppens, B Senut), pp. 21-35. Paris, France: CNRS.

82. McHenry HM. 1991 Petite bodies of the 'robust' australopithecines. Am. J. Phys. Anthropol. 86, 445-454. (doi:10.1002/ajpa.1330860402)

83. Larson SG. 1998 Parallel evolution in the hominoid trunk and forelimb. Evol. Anthropol. 6, 87-99. (doi:10.1002/(SICI)1520-6505(1998)6:3<87::AIDEVAN3>3.0.(0;2-T)

84. Larson SG. 2007 Evolutionary transformation of the hominin shoulder. Evol. Anthropol. 16, 172-187. (doi:10.1002/evan.20149)

85. Drapeau MSM. 2004 Functional anatomy of the olecranon process in hominoids and plio-pleistocene hominins. Am. J. Phys. Anthropol. 124, 297-314. (doi:10.1002/ajpa.10359)

86. Gómez M, Casado A, De Diego M, Arias-Martorell J, Pastor JF, Potau JM. 2020 Quantitative shape analysis of the deltoid tuberosity of modern humans (Homo sapiens) and common chimpanzees (Pan troglodytes). Ann. Anat. 230, 151505. (doi:10. 1016/j.aanat.2020.151505)

87. Bril B, Roux V, Dietrich G. 2005 Stone knapping: Khambhat (India), a unique opportunity? In The necessary conditions for a uniquely hominin behaviour, pp. 53-72. Cambridge, UK: MCDonald Institute for Archaeological Research.

88. Tagliabue M, Ciancio AL, Brochier T, Eskiizmirliler S, Maier MA. 2015 Differences between kinematic synergies and muscle synergies during two-digit grasping. Front. Hum. Neurosci. 9, 165. (doi:10. 3389/fnhum.2015.00165)

89. Steele KM, Tresch MC, Perreault EJ. 2013 The number and choice of muscles impact the results of muscle synergy analyses. Front. Comput. Neurosci. 7, 105. (doi:10.3389/fncom.2013.00105)

90. Rein R, Bril B, Nonaka T. 2013 Coordination strategies used in stone knapping. Am. J. Phys. Anthropol. 150, 539-550. (doi:10.1002/ajpa.22224)

91. Sayers K, Lovejoy C0. 2008 The chimpanzee has no clothes: a critical examination of Pan troglodytes in models of human evolution. Curr. Anthropol. 49, 87-114. (doi:10.1086/523675)

92. Macchi $\mathrm{R}$ et al. 2021 Raw data for: Biomechanical demands of percussive techniques in the context of early stone toolmaking, Dryad, Dataset. (https://doi. org/10.5061/dryad.fxpnvx51) 